\title{
EVOLUÇÃO RECENTE E POTENCIAL DA AGRICULTURA DE BAIXO CARBONO
}

\author{
Marcelo Marques de Magalhães ${ }^{1}$
}

\section{Sérgio Silva Braga Júnior ${ }^{2}$}

Resumo: A agricultura é um setor estratégico na composição das políticas de redução de emissões e sequestro de carbono e o Brasil está entre os países que assumiram voluntariamente um compromisso de redução das emissões de gases do efeito estufa na 15 $5^{\text {a }}$ Conferência das Partes da ONU em 2009. As estratégias de mitigação para o setor da agropecuária foram consolidadas no Plano Setorial de Mitigação e Adaptação às Mudanças Climáticas, o qual deu origem ao Programa de Agricultura de Baixo Carbono. Esse programa é resultado de um esforço para adoção de um novo modelo agrícola, que busca a mitigação da emissão dos gases do efeito estufa, combinada à recuperação de áreas degradadas, proteção e melhor gestão dos recursos naturais, por meio de práticas que visam a melhoria da eficiência na produção. O objetivo deste estudo é avaliar as metas desse Programa em função do potencial de redução das emissões e de sua operacionalização. Esta análise é realizada a partir de dados secundários. A agenda ambiental é resultado de um compromisso voluntário, fruto de uma pressão da sociedade. O plano de governo para a produção de baixo carbono discutido neste texto é apenas um dos instrumentos para atingir as metas acordadas. A questão do reconhecimento das práticas de populações tradicionais e dos sistemas agroecológicos pode ser aprofundada na medida em que o plano desenvolve-se, resolvendo-se questões regionais conforme sua aptidão produtiva e adequação entre os projetos e os condicionantes para seu desenvolvimento.

Palavras-chave: agricultura de baixo carbono, mudanças climáticas, gases do efeito estufa.

\footnotetext{
${ }^{1}$ Universidade Estadual Paulista, Campus Tupã, São Paulo, Brasil. E-mail marcelo@tupa.unesp.br. ${ }^{2}$ Universidade Estadual Paulista, Campus Tupã, São Paulo, Brasil. E-mail sergio@tupa.unesp.br.
} 


\section{INTRODUÇÃO}

As estimativas de produção da safra brasileira de grãos para 2012/13 realizadas pela Companhia Nacional de Abastecimento apontam para o volume de 186,1 milhões de toneladas, a serem colhidas em 53,3 milhões de hectares. A produção apresenta volume recorde, cerca de $12 \%$ acima daquela obtida na safra 2011/2012, enquanto a área colhida cresceu cerca de $3 \%$. A estimativa preliminar para a produtividade média nesta safra poderá avançar para 3,49 t/ha, quase 11\% maior que na safra anterior (Conab, 2013).

A agricultura tem apresentado produtividade crescente nos últimos anos, o que corresponde a uma necessidade de expansão da produção em função da demanda crescente por alimentos e energia. O desafio que se coloca para o setor é combinar os ganhos de produtividade na agropecuária com as preocupações sobre os efeitos adversos das mudanças climáticas. A agricultura contribui com as emissões de gases do efeito estufa tanto a partir do consumo de combustíveis fósseis quanto pelo próprio processo biológico de produção, incluindo-se os processos de decomposição anaeróbia da produção em sistemas alagados e dos resíduos animais. Nos últimos anos o setor agrícola brasileiro tem apresentado incrementos sistemáticos das emissões líquidas de gases do efeito estufa (GEE) (Mozzer, 2011).

A discussão internacional sobre o passivo ambiental provocado pelas práticas agrícolas já está em pauta para ser incorporada nas negociações comerciais internacionais. EUA e Comunidade Europeia caminham na discussão de mecanismos de ajustes de fronteira (tarifas ou subsídios) para tratar do problema do deslocamento da produção para os países onde o custo de poluir é menor (efeito de vazamento). Por enquanto, ainda não há um acordo comercial multilateral sobre a incorporação do passivo gerado pela emissão de gases de efeito estufa. Embora frágil, esse contexto de discussão sobre os efeitos adversos das mudanças climáticas tem produzido iniciativas voluntárias para criação de um ambiente regulatório em nível nacional, para permitir a aplicação de leis ambientais e a mobilização de recursos para investimentos na mitigação da emissão de GEE. O comércio internacional permanece com a questão do tratamento dos custos de adoção das práticas de redução de emissões de GEE em aberto, sem um mecanismo 
comum para a equalização de preços na fronteira, ajustado em função dos conceitos de adaptação, mitigação e eficiência (Seroa da Motta, 2011).

A agricultura é um setor estratégico na composição das políticas de redução de emissões e sequestro de carbono e o Brasil está entre os países que assumiram voluntariamente um compromisso de redução das emissões de GEE na 15a Conferência das Partes da ONU (COP-15) em 2009, confirmadas no ano seguinte, na COP-16 As estratégias brasileiras para atingir as metas assumidas na COP-15 foram ratificadas pela Lei $n$ ํ 12.187, por meio da qual foi instituída a Política Nacional sobre Mudanças do Clima (PNMC). As estratégias de mitigação para o setor da agropecuária foram consolidadas no Plano Setorial de Mitigação e Adaptação às Mudanças Climáticas, visando o desenvolvimento da Economia de Baixa Emissão de Carbono na Agricultura (Plano ABC). Este plano deu origem ao Programa de Agricultura de Baixo Carbono (Programa ABC), implementado em 2010. Esse programa é resultado de um esforço para adoção de um novo modelo agrícola, que busca a mitigação da emissão dos GEE, combinada à recuperação de áreas degradadas, proteção e melhor gestão dos recursos naturais, por meio de práticas que visam a melhoria da eficiência na produção.

O objetivo deste estudo é avaliar as metas do Plano ABC em função do potencial de redução das emissões e da operacionalização do Programa ABC. Esta análise é realizada a partir de dados secundários.

$\mathrm{Na}$ seção 2 apresenta-se as metas, sua distribuição setorial e o papel da agropecuária no Plano Nacional de Mudanças Climáticas (PNMC). Em seguida, apresenta-se o desdobramento das metas no setor agropecuário, estabelecidas no Plano da Agricultura de Baixo Carbono (Plano $A B C$ ). O potencial de redução dessas metas é discutido na seção 4, seguida da análise da operacionalização orçamentária do Programa da Agricultura de Baixo Carbono (Programa ABC), apresentada na seção 5. Na seção final apresentam-se as conclusões.

\section{POLÍTICA NACIONAL DE MUDANÇAS CLIMÁTICAS}

A Política Nacional de Mudanças Climáticas (PNMC) formalizou as metas voluntárias de redução das emissões dos GEE propostas à Convenção-Quadro das 
Nações Unidades sobre Mudança do Clima (UNFCCC), as quais encontram-se na faixa de $36,1 \%$ a 38,9\% em relação às emissões projetadas para 2020. Por outro lado, a PNMC tem autonomia em relação aos acordos internacionais sobre comércio mundial e mudanças no clima. Mais do que as metas, a PNMC estabelece para o país, um marco legal para regulação das ações de mitigação e adaptação do país, definindo princípios, diretrizes e instrumentos para consolidar uma economia de baixo consumo de carbono. A regulamentação da PNMC definiu a distribuição das metas e os parâmetros para projeção das metas e para formulação dos planos setoriais para mitigação das emissões.

A parcela a ser mitigada em 2020 está entre $36,1 \%$ e 38,9\% das emissões totais no mesmo ano, o que corresponde em termos absolutos, aos valores de 1.168 e 1.259 milhões de toneladas de $\mathrm{CO}_{2}$ eq. Descontada a redução proposta, o volume de $\mathrm{CO}_{2} \mathrm{eq}$ emitido em 2020 ficaria entre 2.068 e 1.977 milhões de toneladas métricas. Em relação ao volume de emissões em 2005, a redução estaria entre $6 \%$ e $10 \%$.

As ações de mitigação visando as metas de 2020 estão distribuídas em quatro planos setoriais - mudança no uso da terra e florestas, agropecuária, energia e o conjunto processos industriais e tratamento de resíduos. A projeção das emissões e a distribuição setorial das metas de redução são apresentadas na Tabela 1 a seguir. Nesta são apresentadas duas metas, dadas em função de dois cenários de tendência de crescimento da economia para 2020.

Tabela 1. Compromissos voluntários de redução de GEE.

\begin{tabular}{|c|c|c|c|c|c|c|c|}
\hline \multirow[b]{2}{*}{ Setores } & \multicolumn{3}{|c|}{ Emissões (milhões $\mathrm{t} \mathrm{CO}_{2} \mathrm{eq}$ ) } & \multicolumn{2}{|c|}{ Redução total (\%) } & \multicolumn{2}{|c|}{ Redução (milhões t $\mathrm{CO}_{2}$ eq) } \\
\hline & $\begin{array}{c}\text { Estimativa } \\
2005\end{array}$ & $\begin{array}{c}\text { Projeção } \\
2020\end{array}$ & $\begin{array}{c}\text { Variação } \\
(\%)\end{array}$ & $\begin{array}{l}\text { Meta } \\
36.1 \%\end{array}$ & $\begin{array}{l}\text { Meta } \\
38.9 \%\end{array}$ & $\begin{array}{l}\text { Meta } \\
36.1 \%\end{array}$ & $\begin{array}{l}\text { Meta } \\
38.9 \%\end{array}$ \\
\hline Mudança no uso da terra e florestas & 1268 & 1404 & 10.7 & 24.7 & 24.7 & 801 & 801 \\
\hline Agropecuária & 487 & 730 & 49.7 & 4.9 & 6.1 & 159 & 199 \\
\hline Energia & 362 & 868 & 139.8 & 6.1 & 7.7 & 199 & 248 \\
\hline Processos industriais, tratamento resíduos & 86 & 234 & 172.0 & 0.3 & 0.4 & 10 & 12 \\
\hline Total & 2203 & 3235 & 46.8 & 36.1 & 38.9 & 1168 & 1259 \\
\hline
\end{tabular}

Fonte: Brasil (2009a, 2010)

A projeção das emissões para a mudança de uso da terra, de 1.404 milhões de toneladas $\mathrm{CO}_{2}$ eq considera que $68 \%$ corresponde à Amazônia, 23\% ao Cerrado e $9 \%$ aos biomas Mata Atlântica, Pantanal e Caatinga. Nos demais setores as projeções foram de 730 milhões de toneladas $\mathrm{CO}_{2}$ eq para agricultura, 868 milhões de toneladas $\mathrm{CO}_{2}$ eq para 
energia e 204 milhões de toneladas $\mathrm{CO}_{2}$ eq para processos industriais e tratamento de resíduos. A desagregação das metas atribui maior peso à redução das emissões para mudança no uso da terra (24,7\%), que se traduz em um maior controle sobre o desmatamento, por meio do qual o total das emissões poderia ser reduzido em 801 milhões de $\mathrm{t}$ de $\mathrm{CO}_{2}$ eq. Considerando-se respectivamente os cenários de menor e maior crescimento econômico setorial, as distribuições do restante das metas nos demais setores são de 4,9\% e 6,1\% para agricultura, 6,1\% e 7,7\% para energia, 0,3\% e 0,4\% para processos industriais e tratamento de resíduos.

A projeção das emissões para agricultura em 2020 corresponde a um crescimento de $50 \%$ em relação à emissões de 2005 , o menor entre os setores produtivos. Além da agricultura estar entre os setores que mais contribuem para o crescimento do país, esta transfere parte da eficiência ambiental para o setor energético por meio da substituição de consumo de combustíveis fósseis por biocombustíveis (Cerri et al., 2010). Embora o peso maior nas reduções esteja no controle do desmatamento, caberá à agricultura um maior esforço em relação aos demais setores. O desafio será implantar sistemas produtivos sustentáveis, que mantenham os ganhos de produtividade do setor (Mozzer, 2011).

\section{AGRICULTURA DE BAIXO CARBONO}

Um dos pontos que faz da agricultura um setor estratégico no que diz respeito às políticas mitigatórias dos efeitos adversos das mudanças climáticas é a segurança alimentar. Associada à crescente demanda por alimentos, a agricultura deverá atender também à demanda por biocombustíveis. Esta pressão por expansão da produção é condicionada pelos limites à contribuição para as emissões de GEE, os quais implicam em limites à expansão da área agrícola sobre a vegetação nativa.

As ações para mitigação dos efeitos adversos das mudanças climáticas fazem uso de dois mecanismos complementares, a redução das emissões propriamente dita e o sequestro de carbono no solo e na massa vegetal. A pressão pela manutenção dos ganhos produtivos implicará em melhor eficiência no uso dos insumos, resultando em melhor gestão dos recursos naturais. Medidas de recuperação de áreas degradam, em particular pastagens, associadas ao desenvolvimento da eficiência produtiva, resultarão 
na redução da pressão sobre as áreas de vegetação nativa, contribuindo para o esforço no controle do desmatamento. Por outro lado, o setor agrícola, em função de suas características e sensibilidade, é extremamente vulnerável aos efeitos adversos das mudanças climáticas, distinguindo-se dos demais setores. Portanto a organização e o planejamento das ações a serem realizadas para a adoção das tecnologias de produção sustentáveis para o campo, também tem como objetivo a redução das vulnerabilidades do setor. Os efeitos potenciais de transbordamento dos resultados positivos da implantação de um modelo de produção combinando produtividade e sustentabilidade na agricultura, enfatizam o papel positivo deste setor para as ações de mitigação das emissões de GEE.

A importância das ações voluntárias de mitigação para a inserção no comércio internacional está em dirimir os impactos das medidas de ajustes de fronteira resultantes da transferência de custos de mitigação das emissões de GEE.

Ao enfatizar a importância da manutenção dos níveis de produção agrícola, os países desenvolvidos restringem a troca dos efeitos negativos de ações mitigatórias de emissões sobre a produtividade agrícola. Associada a esta pressão, há uma expectativa de implantação de medidas unilaterais para transferência dos custos de adoção de práticas que resultem em redução de emissões de GEE em setores específicos, por meio de políticas não tarifarias (Seroa da Motta, 2011).

Há ainda, a necessidade de que a UNFCCC reconheça a contribuição das medidas para redução das emissões na agricultura para a integridade do sistema climático global. Os mecanismo específicos para o setor deveriam considerar a contribuição da redução do desmatamento e dos sistemas de produção sustentáveis, as contribuições adicionais dos efeitos de mitigação, entre as quais o sequestro de carbono no solo e biomassa.

Embora não haja um acordo internacional, os países com maior contribuição mundial nas emissões avançam na introdução de medidas setoriais de mitigação. A ausência de um acordo multilateral, abre espaço para a aplicação unilateral de mecanismos de equalização de preços do mercado interno em relação ao internacional. As ações para a implantação de um modelo agrícola de baixo carbono deverão contribuir para minimizar o impacto das medidas de ajuste de fronteira sobre a competividade brasileira no mercado internacional de produtos agrícolas.

O Plano para Agricultura de Baixo Carbono (Plano ABC) foi instituído em 2010 e compõe o conjunto de planos setoriais resultantes da PNMC. Além das ações para reduzir 
ou evitar as emissões de GEE, foi estabelecido um componente de apoio à implantação das ações para a capacitação dos técnicos e produtores, financiamento de pesquisa e desenvolvimento e monitoramento das atividades e resultados (Brasil, 2010).

Em termos de metas físicas, o Plano ABC tem como objetivos: (i) promover a recuperação de 15 milhões dos atuais 60 milhões de hectares de pastagens degradadas; (ii) promover sistemas de integração entre lavoura, pecuária e floresta em 4 milhões de hectares; (iii) ampliar a prática de plantio direto em 8 milhões, sobre os atuais 25 milhões de hectares; (iv) ampliar o uso da técnica de fixação biológica de nitrogênio em mais 5,5 milhões de hectares; ( $v$ ) implantar 3 milhões de hectares de florestas plantadas, ao lado do plano setorial que prevê mais 5 milhões de hectares para siderurgia e; (vi) promover o tratamento de 4,4 milhões de $\mathrm{m}^{3}$ de dejetos da produção animal.

Ainda em 2010, o Plano ABC já contava com recursos do governo federal para o financiamento de investimentos, dentro do Plano Agrícola e Pecuário (Plano Safra 2010/11) do Ministério da Agricultura, Pecuária e Abastecimento (MAPA). A partir de 2011, as ações do Plano $A B C$ passaram a integrar o Programa para Redução da Emissão de Gases de Efeito Estufa na Agricultura (Programa ABC), dentro do Plano Safra 2011/12.

Os objetivos do Programa $A B C$ são: (i) reduzir as emissões de gases do efeito estufa oriundas das atividades agropecuárias; (ii) reduzir o desmatamento; (iii) adequar as propriedades rurais à legislação ambiental; (iv) ampliar a área de florestas cultivadas; (v) estimular a recuperação de áreas degradadas. Ainda que alguns objetivos não sejam exatamente dirigidos à redução das emissões, como a recuperação de pastagens degradadas, estes podem aumentar a eficiência no uso dos recursos naturais, minimizando a pressão sobre áreas de vegetação natural.

O Programa $A B C$ financia projetos produtivos dentro das seguintes finalidades: (i) recuperação de pastagens degradadas ( $A B C$ Recuperação); (ii) implantação e melhoramento de sistemas orgânicos de produção agropecuária (ABC Orgânico) ${ }^{3}$; (iii) implantação e melhoramento de sistemas de plantio direto na palha (ABC Plantio Direto); (iv) implantação e melhoramento de sistemas de integração lavoura-pecuária (iLP),

\footnotetext{
${ }^{3}$ Ainda não há estudos conclusivos a respeito dos efeitos diferenciais dos sistemas orgânicos de produção sobre as emissões de GEE (FGV, 2013). Por outro lado, os sistemas orgânicos são caracterizados por pequena escala de produção, baixa intensidade no uso de insumos externos e alto grau de emprego da mão-de-obra. Estes podem ser uma alternativa para pequenos produtores, com limitado acesso à terra e alta disponibilidade de mão-de-obra familiar.
} 
pecuária-floresta ou lavoura-pecuária-floresta (iLPF) e de sistemas agroflorestais (SAF) (ABC Integração); (v) implantação, manutenção e melhoramento do manejo de florestas comerciais, inclusive aquelas destinadas ao uso industrial ou à produção de carvão vegetal (ABC Florestas); (vi) adequação ou regularização das propriedades rurais frente à legislação ambiental, incluindo recuperação da reserva legal e de áreas de preservação permanente, recuperação de áreas degradadas e implantação e melhoramento de planos de manejo florestal sustentável (ABC Ambiental); (vii) tratamento de dejetos e resíduos oriundos da produção animal para a geração de energia e compostagem (ABC Tratamento de Dejetos); (viii) implantação, melhoramento e manutenção de florestas de dendezeiro, prioritariamente em áreas produtivas degradadas (ABC Dendê); (ix) estímulo ao uso da fixação biológica do nitrogênio (FBN) (ABC Fixação Biológica de Nitrogênio).

Os atuais objetivos e linhas de financiamento são resultados de modificações introduzidas com o desenvolvimento do Programa. Em 2012 foram introduzidas linhas específicas para financiamento de custeio, comercialização e investimentos em sistemas orgânicos de produção. A implantação e manutenção de florestas de dendezeiros com prioridade para recuperação de áreas produtivas degradadas também passou a fazer parte do programa. Esta atividade também é parte do Programa de Produção Sustentável de Palma de Óleo no Brasil, lançado em 2010. No início do Programa ABC a taxa de juros era de $5,5 \%$ passando a $5 \%$ na safra $2012 / 13$, com o objetivo de diminuir a diferença em relação aos juros praticados em programas alternativos.

\section{POTENCIAL DE REDUÇÃO DAS EMISSÕES}

A maior parte das emissões brasileiras de GEE na primeira década deste século foi produzida pelo desmatamento, para dar lugar à agricultura e pecuária, principalmente na Amazônia. Cerri et al. (2009, 2010) fizeram uma análise da contribuição efetiva e compartilhada das atividades agropecuárias com o objetivo de identificar as melhores opções de mitigação para o Brasil. Primeiro são apresentadas as principais fontes e as estimativas de sua contribuição nas emissões. Em seguida é feita uma avaliação do potencial de mitigação de práticas agrícolas e pecuárias selecionadas, incluindo sistemas integrados de produção. 


\section{PRINCIPAIS FONTES BRASILEIRAS DE EMISSÃO DE GEE}

A análise das fontes de emissões realizada por Cerri et al. $(2009,2010)$ tomou como referência a metodologia do Painel Intergovernamental de Mudanças Climáticas (IPCC) para inventário de emissão de GEE, o qual considera a agricultura como parte do setor Uso do Solo, Mudança no Uso do Solo e Floresta (LULUCF). Este setor é subdividido em dois subsetores: (i) Uso do Solo e Floresta e (ii) Agricultura. O primeiro representa as emissões e a extração pelo desmatamento da vegetação nativa, mudanças no estoque de biomassa madeireira, abandono de áreas de manejo florestal e do estoque no solo. O subsetor agrícola representa a emissão de GEE por fermentação entérica, manejo de dejetos, cultivos alagados, queima dos resíduos agrícolas e perdas no estoque do solo agrícola. As emissões por uso de fertilizantes químicos, orgânicos, urina e esterco animal, resíduos vegetais são contabilizados em solos agrícolas.

O primeiro relatório brasileiro sobre emissão de gases do efeito estufa refere-se ao período de 1990 a 1994, no qual essas foram estimadas em 1.728 milhões de toneladas de $\mathrm{CO}_{2}$ eq. As principais fontes identificadas foram: (i) desmatamento florestal, responsável por mais da metade das emissões de GEE brasileiras (56,3\%); (ii) combustíveis fósseis (15,8\%); (iii) fermentação entérica (13\%) e; (iv) solos agrícolas $(9,8 \%)$.

As emissões globais de GEE cresceram 17\% no período de 1994 a 2005. As emissões brasileiras cresceram 48,9\%, na China cresceram 88,8\% e na Índia, 62,1\%. A variação nas emissões brasileiras de GEE estimada em termos absolutos foi de 294,3 milhões de toneladas de $\mathrm{CO}_{2}$ eq no mesmo período. Os subsetores que mais contribuíram nesta variação foram combustíveis fósseis (36\% do aumento), agricultura (33\%) e mudança no uso da terra e florestas (24\%). Dentro do subsetor agrícola, fermentação entérica e solos agrícolas foram responsáveis por $99 \%$ das emissões, sendo $53 \%$ para o primeiro e $46 \%$ para o segundo.

A agricultura tem papel estratégico para redução das emissões por contribuir direta ou indiretamente com a mitigação em outros setores. $O$ aumento da produtividade no campo reduz a pressão para o desmatamento e a produção de bicombustíveis amplia o leque de fontes renováveis para substituição dos combustíveis fósseis. Os resultados de estudos acadêmicos e de pesquisa e desenvolvimento apresentados a seguir oferecem 
uma breve avaliação sobre a contribuição de práticas e atividades agropecuárias que combinam sustentabilidade e produtividade, entre elas o plantio direto, o complexo sucroalcooleiro, a recuperação de pastagens degradadas e a intensificação da pecuária.

\section{PLANTIO DIRETO}

O cultivo em sistema de plantio direto tem como objetivo evitar o tombamento da camada inferior do solo para aeração desta. A redução no movimento do solo evitaria perdas de carbono, reduzindo as emissões quando comparado ao cultivo convencional.

A capacidade de sequestro de carbono no solo está sujeita a uma série de fatores ambientais e técnicos. O tipo de clima predominante na região, a variação climática, as variações nas práticas implementadas, a variação na quantidade e na qualidade de resíduos culturais (relação entre carbono e nitrogênio) estão entre os fatores que afetam o processo de fixação de carbono no solo. Deve-se considerar que a quantidade que pode ser acumulada tem um teto, dado por uma condição de equilíbrio limitante do processo de sequestro. A profundidade considerada na avaliação do estoque no solo também pode reportar resultados incompatíveis entre diferentes estudos. Por último, os ganhos por fixação de carbono no solo são reversíveis em função da variação nos próprios fatores já apontados anteriormente (Smith et al., 1998; apud Cerri et al., 2009:839).

As estimativas para acúmulo de carbono no solo apresentadas em Carvalho et al. (2010), indicam que no Cerrado, o plantio direto pode sequestrar 1,47 Mg de carbono por hectare ao ano. O plantio direto associado ao sistema de integração lavoura-pecuáriafloresta, pode reter entre 0,8 e 2,8 Mg de carbono por hectare ao ano.

\section{COMPLEXO SUCROALCOOLEIRO}

O complexo de produção de açúcar e etanol pode contribuir com a redução das emissões em três diferentes processos.

O primeiro processo diz respeito à substituição da gasolina por etanol, o qual produz o efeito de maior impacto entre três. Embora o consumo de combustíveis tenha 
sido crescente entre 1994 e 2005, a estimativa para o efeito substituição foi de 10 milhões de toneladas de carbono que deixaram de ser lançados por ano no período.

O segundo refere-se ao uso do bagaço da cana-de-açúcar como combustível para produção de vapor e eletricidade. O efeito substituição da energia convencional para energia de bagaço foi estimado em 8 milhões de toneladas que deixaram de ser emitidas em 1998 (Cerri et al., 2009). A vinhaça é um segundo subproduto que pode ser utilizado na produção de gás metano, evitando a emissão de 0,05 milhões de toneladas de carbono por ano (Macedo 1998; apud Cerri et al., 2009).

O terceiro processo de contribuição para a mitigação dos GEE é a mecanização da colheita da cana-de-açúcar em substituição à pratica de queimada. As restrições para queimada no Estado de São Paulo tiveram início em 2000 e espera-se que até 2020 mais de $80 \%$ das áreas sejam colhidas mecanicamente. Além de evitar a queima da matéria orgânica no perfil superficial do solo, a colheita mecânica deixa a palha residual sobre solo. Um contraponto é dado pela reforma do canavial realizada a cada 6 ou 7 colheitas, que pode reduzir o carbono acumulado nos anos anteriores. O sequestro líquido em solo cultivado por cana-de-açúcar é estimado em 0,48 Mt C por ano (Feller, 2001; apud Cerri et al., 2009).

Considerando-se a área estimada em colheita mecânica em 1,5 milhões de hectares (final da década passada), a combinação das reduções nos três processos resultou na redução das emissões em 18,5 milhões de toneladas por ano, o que corresponde a 67,9 milhões de toneladas de $\mathrm{CO}_{2}$ eq anuais.

\section{RECUPERAÇÃO DE PASTAGENS DEGRADADAS}

A taxa média brasileira de ocupação das pastagens é de 0,9 unidade animal (UA) por hectare. Do ponto de vista ambiental, a importância em aumentar a taxa de ocupação na pecuária está na redução da pressão sobre as áreas de vegetação nativa. Para seguir os objetivos de intensificação do uso das pastagens em conjunto com a melhoria da competitividade, a lógica de gestão da produção pecuária deve substituir a avaliação do retorno por unidade animal para o retorno por unidade de área. 
A qualidade das pastagens tem sido o grande desafio da pecuária, diante dos avanços já obtidos por melhoramento genético, aumento da resistência animal a patógenos e melhoria na qualidade do produto final. Pedreira e Zimmer (2011) mostram que a recuperação de pastagens pode elevar a lotação animal de 0,76 UA/ha para uma taxa de ocupação acima de 2 UA/ha, aumentando a margem líquida de $R \$ 19 /$ ha para mais de $R \$ 360 /$ ha (dados referente à recuperação de pastagem no Estado do Mato Grosso, 2006).

No sistema integrado entre lavoura e pecuária, a introdução da lavoura na operação de reforma da pastagem, mostra-se como uma estratégia tecnicamente viável para a transição de um sistema convencional para um sistema integrado de baixo custo produzindo pastagens de alta qualidade (Cerri et al., 2009). Forragens de baixo valor nutritivo aumentam a demanda por maior volume de alimentos, gerando uma pressão adicional para aumento da área ocupada.

O manejo do gado em piquetes de alimentação é uma técnica que permite a intensificação da produção pecuária, tanto em relação à área ocupada, quanto ao tempo de abate. Neste sistema há um melhor aproveitamento da pastagem na estação seca. Por sua vez, o abate precoce, ao reduzir o tempo de permanência dos animais em alimentação, contribui para a redução das emissões de GEE por fermentação entérica. Uma estratégia complementar para diminuir a fermentação está no uso de suplementos alimentares, mas este é limitado por provocar efeitos colaterais nos animais.

Carvalho et al. (2010) apresentou estimativas para contribuição da recuperação de pastagens degradadas na Amazônia e no Cerrado para a mitigação das emissões de carbono. Na Amazônia, os solos podem acumular de 2,7 a 6,0 Mg de carbono por hectare ao ano. No Cerrado, o acumulo pode ser de 0,94 Mg de carbono por hectare por ano.

\section{SISTEMAS DE INTEGRAÇÃO LAVOURA-PECUÁRIA-FLORESTA (ILP, ILPF)}

A Empresa Brasileira de Pesquisa Agropecuária (EMBRAPA) vem pesquisando e desenvolvendo soluções adaptadas para integração lavoura-pecuária-floresta em campos experimentais das Unidades de Referência Técnica (URT/iLPF). Estas são distribuídas 
nas 5 macrorregiões brasileiras. Parte dos resultados preliminares á compilada brevemente a seguir.

Wruck (2011) avaliou os resultados de um sistema com integração lavourapecuária combinando plantio de verão e inverno, de soja, arroz, milho/sorgo e milheto/crotalária. A carga animal chegou a 5 UA/ha na época das águas ocupando 40 ha e 2 UA/ha na seca para 100 ha. Ao final, a carga média do rebanho permaneceu em 1,1 UA/ha, mas com ganho de peso de 200 a $210 \mathrm{Kg}$ dos 8-9 aos 15-16 meses e produtividade da soja perto de 60 sacas de $60 \mathrm{Kg} / \mathrm{ha}$ e de arroz entre 25 e $50 \mathrm{Kg} / \mathrm{ha}$, considerando-se a variação sazonal entre as épocas das secas e das águas.

Pedreira e Zimmer (2011) avaliaram os rendimentos de um sistema de integração lavoura-pecuária-floresta em seus primeiros anos de implantação. O sistema integrava 0 cultivo de arroz, soja e eucalipto à pecuária, com a introdução tardia desta última atividade. A receita líquida do sistema integrado (somente lavoura e floresta) chegou a ser $49 \%$ maior do que o cultivo solteiro da lavoura no primeiro ano. Nos dois anos seguintes, as adversidades climáticas afetaram negativamente a produção em ambos os sistemas, aproximando os rendimentos. Adicionalmente, foram observados problemas no ajuste de espaçamento entre fileiras de plantas. O sistema de plantio ainda requer pesquisa e desenvolvimento para adaptação da tecnologia de acordo com as características edafoclimáticas regionais. Não foram produzidas estimativas de mitigação.

Salton (2005) apud Carvalho (2010), avaliou o sequestro de carbono em sistemas de produção agropecuária no Cerrado e observou maiores estoques de carbono na presença de forrageiras. A ordem decrescente de estoque de carbono acumulado segundo o sistema produtivo é dada por: pastagem permanente, integração lavourapecuária em plantio direto, lavoura em plantio direto, lavoura em cultivo convencional.

\section{FINANCIAMENTO DA AGRICULTURA DE BAIXO CARBONO}

O volume total de recursos para aplicação no Plano ABC entre 2011 e 2020 é de $R \$ 197$ bilhões, dos quais $R \$ 157$ bilhões devem ser disponibilizados via crédito rural para atingir as metas físicas operacionalizadas no programa (fontes orçamentárias ou linhas de 
crédito). Os demais são recursos financeiros provenientes de diversas fontes (BNDES, recursos próprios dos bancos privados).

Os primeiros recursos para o Plano ABC já estavam disponíveis em 2010, com a criação da linha de crédito agrícola para o financiamento de tecnologias sustentáveis sob o desenho do Programa $A B C$, correspondente ao volume de $R \$ 2$ bilhões, com juros de 5,5\% ao ano. Esses recursos não foram mobilizados até o final de 2010.

A alocação dos recursos iniciais no Banco Nacional de Desenvolvimento Econômico e Social (BNDES) pode ter dificultado a operacionalização desses, em parte pelo próprio limite de montante por projeto dado pelas regras do programa ( $\mathrm{R} \$ 1$ milhão). O BNDES tem baixa capilaridade e talvez tenha mais eficiência na gestão de contratos de maior valor. A entrada do Banco do Brasil (BB) na operacionalização do programa a partir da safra 2011/12 promoveu o aumento do número de contratos e do consequente volume total alocado.

A capilaridade do Banco do Brasil em termos de distribuição de agências praticamente em todo território nacional (5130 municípios), associada às relações locais com as instituições representantes dos produtores (sindicato rural) e a parceria com as redes pública e privada de técnicos da agropecuária são características que contribuíram para o avanço do programa. Este período também foi acompanhado pela incorporação dos Programas Produsa e Propflora (contratos operacionalizados do BNDES) no Plano ABC e por uma leve redução na taxa de juros, de 5,5\% para 5,0\% ao ano. Um corte mais agressivo nos juros, poderia ter contribuído ainda mais para tornar ampliar a ação do programa.

Até maio/2013 foram aplicados $\mathrm{R} \$ 4,3$ milhões, para cerca de 16,4 mil contratos (Tabela 2). O valor médio por projeto foi de $R \$ 261,2$ mil, mas vem apresentando evolução crescente ao longo dos anos, chegando a $\mathrm{R} \$ 288,9$ mil na safra 2012/13. Alocar $R \$ 157$ bilhões em 10 anos, implicaria em contratar o volume médio de $R$ \$15,7 bilhões ao ano. Considerando o valor médio dos contratos atuais, seriam necessários cerca de 530 mil contratos por ano para atingir a meta de aplicação dos recursos do programa em 2020. Para que o programa avance, além da divulgação, treinamento técnico e do desenvolvimento da capacidade de absorção tecnológica, talvez seja necessária uma ampliação do valor máximo por contrato, da taxa de juros e do prazo, à capacidade de pagamento do contratante, o qual depende diretamente do perfil de rendimento das 
atividades financiadas, em curto e longo prazo. O valor médio dos contratos poderia aumentar em função dessa adequação permitindo a plena realização das metas dentro do prazo proposto.

Claramente há espaço para crescer em termos do número de operações e do montante contratado por operação. Por outro lado, os juros de 5,0\% são relativamente superiores aos juros de programas alternativos, como o Fundo Constitucional do CentroOeste (FCO), o qual oferece recursos para investimentos na agropecuária com juros entre $3,0 \%$ e 4,1\% ao ano. A partir de 2012, o Fundo Constitucional do Centro-Oeste passou a contar com uma linha específica para financiamento dos projetos do Programa ABC. São duas modalidades, conservação da natureza e projetos de integração lavoura-pecuáriafloresta. Além de acelerar a adesão aos projetos do Programa ABC, essa medida pode contribuir para intensificar o uso de recursos na região Centro-Oeste, promovendo menor pressão sobre a fronteira de ocupação das reservas do bioma Cerrado.

Tabela 2. Programação e aplicação dos recursos do Programa ABC de 2009/10 a 2012/13.

\begin{tabular}{ccrrrrr}
\hline \multirow{2}{*}{ Safra (1) } & $\begin{array}{c}\text { Programação } \\
\text { (R\$ milhões) }\end{array}$ & $\begin{array}{c}\text { Aplicação } \\
\text { (R\$ milhões) }\end{array}$ & $\begin{array}{c}\text { Desembolso } \\
\text { relativo (\%) }\end{array}$ & $\begin{array}{c}\text { Número de } \\
\text { contratos }\end{array}$ & $\begin{array}{c}\text { Valor médio } \\
\text { (R\$ mil) }\end{array}$ \\
\hline (a) & (b) & (b/a) & (c) & (b/c) \\
\hline $2009 / 10$ & 2000.0 & - & - & - & - \\
$2010 / 11$ & 3150.0 & 418.5 & 13.3 & 2910 & 143.8 \\
$2011 / 12$ & 3150.0 & 1127.5 & 35.8 & 4015 & 280.8 \\
$2012 / 13$ & 3400.0 & 2736.6 & 80.5 & 9473 & 288.9 \\
$2013 / 14$ & 4000.0 & - & - & - & - \\
\hline
\end{tabular}

Fonte: MAPA a partir dos dados do BNDES e BB (2013).

Notas: (1) Refere-se ao ano safra, de julho a maio do ano seguinte.

A distribuição dos recursos segundo as linhas de financiamento do Programa ABC, considerando-se os dados disponíveis para os primeiros seis meses da safra de 2012/13, mostravam a concentração de investimentos em recuperação de pastagens degradadas (77\% do montante aplicado), uma pequena parcela aplicada em plantio direto (7\%), conservação da natureza via FCO (6\%), florestas $(4,6 \%)$, integração lavoura-pecuáriafloresta $(4,1 \%)$ e menos de $1 \%$ em projetos de tratamento de dejetos, produção orgânica e preservação ambiental via ABC (FGV, 2013 a partir de dados do Banco do Brasil). 
A distribuição regional dos recursos do Programa $A B C$ parece não seguir uma racionalidade técnica para maior impacto sobre mitigação das emissões e sequestro dos gases de efeito estufa (Tabela 3). As regiões Sul e Sudeste são aquelas que recebem a maior parte dos recursos e que concentram a maior parte dos contratos. Considerando-se os objetivos finais do programa, seria mais interessante que os recursos fossem focalizados nas regiões Norte, Nordeste e Centro Oeste - regiões estas mais susceptíveis às mudanças climáticas globais (Féres, Reis e Speranza, 2011).

$A$ adoção da tecnologia promovida pelo Programa $A B C$ encontra-se concentrada nas macro regiões Sul e Sudeste. Essa concentração poderá contribuir para a intensificação das desigualdades regionais em um futuro não muito distante, da mesma forma que aconteceu com a difusão tecnológica no processo de modernização da agricultura dos anos 1970.

Tabela 3. Desembolsos do Programa ABC segundo macro regiões no primeiro semestre da safra 2012/13.

\begin{tabular}{lcrrrr}
\hline \multirow{2}{*}{ Região } & \multicolumn{2}{c}{ Número de contratos } & \multicolumn{2}{c}{ Desembolso } & \multicolumn{2}{c}{\begin{tabular}{c} 
Valor Médio \\
\cline { 2 - 5 }
\end{tabular}} & \multicolumn{1}{c}{ (unidade) } & \multicolumn{1}{c}{$(\%)$} & \multicolumn{1}{c}{ (R\$ mil) } & (\%) & (R\$ mil) \\
\hline Centro-Oeste & 732 & 16.0 & 383134.9 & 22.3 & 523.4 \\
Nordeste & 205 & 4.5 & 87966.6 & 5.1 & 429.1 \\
Norte & 176 & 3.9 & 69023.2 & 4.0 & 392.2 \\
Sudeste & 2100 & 46.0 & 784288.3 & 45.7 & 373.5 \\
Sul & 1350 & 29.6 & 392598.8 & 22.9 & 290.8 \\
\hline Total & 4563 & 100.0 & 1717011.8 & 100.0 & 376.3 \\
\hline
\end{tabular}

Fonte: FGV (2013) a partir dos dados do MAPA.

\section{CONCLUSÃO}

O Plano para Agricultura de Baixo Carbono poderá atingir a meta das reduções de emissão de gases de efeito estufa conforme estabelecido de maneira voluntária na reunião COP-15. Sua implementação apresentou percalços no início, tem sido 
relativamente lenta, mas ainda há tempo hábil para retomar o ritmo em busca dos objetivos do plano.

Além da virtude dada pela própria natureza das metas buscadas, o Plano ABC tem pontos positivos implícitos em sua própria formulação. Primeiro tem uma motivação voluntária, mas com uma planificação estratégica de médio prazo para uma política ambiental aplicada à agricultura. Promove a convergência de políticas ambientais que tem como característica natural um amplo espectro de objetivos. O plano não oferece explicitamente instrumentos para organizar o uso do solo, mas pode contribuir com a organização da expansão agropecuária no Centro-Oeste e Amazônia.

Em termos de política comercial, a Agricultura de Baixo Carbono é parte de uma estratégia de longo prazo para posicionamento no mercado internacional, respeitando-se as condições não comerciais acordadas em acordos multilaterais.

Embora o Brasil tenha trabalhado para uma articulação entre os países emergentes do hemisfério Sul (Brasil, Índia, África do Sul e China), a questão ambiental ainda encontra-se em processo de desenvolvimento para a formação de um posicionamento mais adequado da política externa brasileira.

Do ponto de vista interno, a agenda ambiental internacional não pode ser interpretada de maneira restrita, apenas como um argumento protecionista dos países desenvolvidos para barrar as exportações brasileiras. Essa interpretação gera uma posição equivocadamente defensiva. Ao contrário, a agenda ambiental é resultado de um compromisso voluntário, fruto de uma pressão da sociedade. O plano de governo para a produção de baixo carbono discutido neste texto é apenas um dos instrumentos para atingir as metas acordadas. O plano é fundamentado na promoção de técnicas de redução de emissões e sequestro de carbono, desenvolvimento da produtividade e consequente redução da pressão para o desmatamento da vegetação nativa. A questão do reconhecimento das práticas de populações tradicionais e dos sistemas agroecológicos pode ser aprofundada na medida em que o plano desenvolve-se, resolvendo-se questões regionais conforme sua aptidão produtiva e adequação entre os projetos e os condicionantes para seu desenvolvimento.

No balanço do comércio internacional o Brasil poderia ser considerado como um credor ambiental. Os biomas brasileiros - Floresta Amazônica, Pantanal, Cerrado, Caatinga, Mata Atlântica - contribuem para a preservação de recursos genéticos de 
interesse mundial e geram serviços ambientais de regulação climática, as quais são questões ambientais de alcance global. Embora reconhecida, a remuneração desses serviços não se realiza de forma efetiva. Caberia ao Brasil negociar a execução efetiva dessas compensações nos órgãos multilaterais de desenvolvimento e diretamente com os importadores desses serviços.

A interpretação da questão ambiental não pode se restringir a um problema. Além dos ganhos provenientes do desenvolvimento da produtividade e eficiência na agricultura, a questão ambiental articulada às políticas comerciais pode resultar em benefícios sociais e econômicos para o Brasil.

\section{BIBLIOGRAFIA}

BRASIL. Inventário brasileiro das emissões e remoções antrópicas de gases de efeito estufa: informações gerais. Brasília: Ministério da Ciência e Tecnologia, 24/nov./2009. 2009a.

BRASIL. Lei Federal no 12.187, de dezembro de 2009. Politica Nacional das Mudanças Climáticas. Brasília: Congresso Nacional. 2009b.

BRASIL. Decreto no 7.390, de 9 de dezembro de 2010. Regulamenta os Artigos 6o, 11 e 12 da Lei no 12.187, de 29 de dezembro de 2009, que institui a Politica Nacional sobre Mudança do Clima (PNMC), e dá outras providencias. Brasília: Presidência da República. 2010.

Carvalho, J. L. N.; Avanzi, J. C.; Silva, M. L. N.; Mello, C. R.; Cerri, C. E. P. Potencial de sequestro de carbono em diferentes biomas do Brasil. Revista Brasileira Ciências do Solo. 2010, vol.34, n.2, pp. 277-290. 2010.

Cerri, C. C.; Maia, S. M. F.; Galdos, M. V.; Cerri, C. E. P.; Feigl, B. J.; Bernoux, M. Brazilian greenhouse gas emissions: the importance of agriculture and livestock. Sci. Agric. Piracicaba: ESALQ. v.66, n.6, p.831-843. Nov./Dec. 2009.

Cerri, C. C.; Bernoux, M. Maia, S. M. F.; Cerri, C. E. P.; Costa Junior, C.;Feigl, B. J.; Frazão, L. A.; Mello, f. F. C.; Galdos, M. V.; Moreira, C. S.; Carvalho, J. L. N. Greenhouse gas mitigation options in Brazil for land-use change, livestock and agriculture. Sci. Agric. Piracicaba: ESALQ. v.67, n.1, p.102-116. Jan./Feb. 2010.

CONAB. Acompanhamento de safra brasileira: grãos, décimo primeiro levantamento, agosto/2013. Brasília: CONAB. 2013. 29p. 
CONDEL/FCO. Fundo Constitucional de Financiamento para o Centro-Oeste: programação para 2012. 1 $1^{\text {a }}$. edição, Brasília: Ministério da Integração Nacional. 2012. $57 p$.

Féres, Reis, Speranza. Impactos das mudanças climáticas no setor agrícola brasileiro. In: Seroa da Motta, R.; Hargrave, J.; Luedermann, G.; Gutierrez, M. B. S. (ed.). Mudança climática no Brasil: aspectos econômicos, sociais e regulatórios. Rio de Janeiro: IPEA. P.301-311. 2011.

FGV. Agricultura de baixa emissão de carbono: a evolução de um novo paradigma. São Paulo: FGV. 204p. (Relatório de pesquisa) Observatório ABC - Centro de Agronegócio da Escola de Economia de São Paulo, FGV. 2013.

Mozzer, G. B. Agropecuária no contexto da economia de baixo carbono. In: Seroa da Motta, R.; Hargrave, J.; Luedermann, G.; Gutierrez, M. B. S. (ed.). Mudança climática no Brasil: aspectos econômicos, sociais e regulatórios. Rio de Janeiro: IPEA. p.111-125. 2011.

Pedreira, B. C.; Zimmer, A. H. Estratégias de recuperação de pastagens. Cuiabá: Embrapa Agrossilvipastoril e Embrapa Gado de Corte, nov./2011. 164p. (mimeo)

Seroa da Motta, R. A política nacional sobre mudança do clima: aspectos regulatórios e governança. In: Seroa da Motta, R.; Hargrave, J.; Luedermann, G.; Gutierrez, M. B. S. (ed.) (2011). Mudança climática no Brasil: aspectos econômicos, sociais e regulatórios. Rio de Janeiro: IPEA. p.31-40. 2011

Seroa da Motta, R. Desafios ambientais da economia brasileira. Texto para discussão $n$. 509. Rio de Janeiro: IPEA. 1997. 28p. ISSN 1415-4765.

Wruck, F. J. Conceitos de integração lavoura-pecuária-floresta (iLPF). Cuiabá: Embrapa Arroz e Feijão, nov./2011. 35p. (mimeo) 